\section{ON THE DAILY LABOURING FORCE OF THE HUMAN HEART}

II.

IT remains for me to explain the manner in which the two elements of the calculation of the daily labouring force of the heart (see p. 255) have been ascertained. These elements are, the capacity of the left ventricle of the heart, and the hydrostatical pressure of the blood inside the ventricle at each pulse.

The average capacity of the left ventricle is ascertained by filling it with melted wax, at a pressure equivalent to that of $9 \mathrm{ft}$. vertical, of blood ; and afterwards weighing the solidified wax cast of the ventricle and comparing its weight with that of a known volume of the same wax. In this manner, it has been found that the average capacity of the left ventricle does not differ much from 3 ounces.

In the unavoidable absence of any direct experiment on the hydrostatical pressure of the blood in human arteries, we are obliged to have recourse to indirect methods of estimating its amount. The first attempt made by me was the following:- On the 22nd of March, I863, I had an opportunity of witnessing the removal of a large fibrocellular tumour from the left groin of a middle-aged, large sized man, in the operating theatre of the Meath Hospital. In the course of the operation, the external epigastric artery (which appeared enlarged to feed the tumour) was divided, and before it could be ligatured, strong jets of blood were thrown from it in various directions about the floor of the theatre. I noticed, as the poor fellow struggled on the operating table, that the jets of blood fell short, or enjoyed a longer range, according to the angle of elevation of the orifice of the bleeding artery, and that there was a certain maximum range on the floor of the theatre, which was not exceeded. Having afterwards measured the vertical height of the bleeding artery, and the horizontal distance of the squirts of blood corresponding to the maximum range, I found them to be $3 \mathrm{ft} .6 \mathrm{in}$. and $s \mathrm{ft}$. respectively. From these data, I readily calculated (by the parabolic theory of maximum range of projectiles on a descending inclined plane) the velocity of the blood issuing from the orifice of the artery, and found it to be $12.905 \mathrm{ft}$., corresponding to an hydrostatical pressure of $2.586 \mathrm{ft}$.

This result, although of great value, leaves us still in ignorance of the hydrostatical pressure of the blood inside the arteries when they are intact; for, owing to the wonderful perfection of the mechanism of the heart, its force of contraction is exactly regulated by the resistance it is compelled to overcome, and as soon as a large artery is opened, the heart instinctively feels that the resistance is lessened, and spontaneously reduces its force of contraction, to correspond with the diminished resistance of the circulation. The beneficial effects of this remarkable property of the heart, in the case of wounded arteries, are evident, for its reduced force of contraction greatly diminishes the loss of blood.

Dr. Hales, in the course of his Hæmastatics, remarks that the blood did not spout much higher than 2 feet from the wounded artery of the horse, although the pressure inside the arteries, when the circulation is complete, exceeded 9 feet of blood. The difference in the force of the heart in the two cases arises from the resistance offered by the capillary circulation.

We find ourselves, therefore, obliged to estimate the force of the hremastatical pressure in the hmman arteries, not by direct experiment, but by the following indirect reasoning.

The experiments of Poiseuille on the discharge of liquids through capillary tubes, prove that the resistance offered by such tubes is directly proportional to the length of the tubes and inversely proportional to the squares of their cross sections.
The quantity of liquid discharged by a capillary tube in a given time is inversely proportional to this resistance, and may be expressed by the following formula:-

$$
\mathrm{Q}=\mathrm{A} \times \frac{h \mathrm{l}^{4}}{l}
$$

In this expression $Q$ denotes the quantity of liquid discharged in a given time, $\mathrm{A}$ is a constant, $h$ denotes the charge or hydrostatical pressure, and $d$ and $l$ are the diameter and length of the capillary tube.

Now, there is reason to believe that in animals, similar in bulk, the arrangement and structure of the capillaries are such that the ratio of the squares of their cross sections to the total lengths of the capillaries is practically constant, as may be proved from the following comparison of the sheep and dog. The left ventricle of a sheep's heart, according to Hales, contains I 85 cubic inches, and its pulse beats 65 times in a minute; the quantity of blood passing through its capillaries in a given time being obviously proportional to the product of these two quantities. The hemastatical pressure in the arteries of the sheep (Hales) is 6.46 feet of blood.

If we bring to the left hand side of equation ( $I$ ) the quantities depending on capillary resistance, we find

$$
\mathrm{A} \times \frac{d^{4}}{l}=\frac{\mathrm{Q}}{h}=\frac{1.85 \times 65}{6.46}=18.6 \text {. }
$$

The number thus found is to be regarded as the capillary coefficient of the sheep. The average of the capacities of the left ventricles of six dogs measured by Dr. Hales, was 0.954 cubic inches; and the average hamastatical pressure in the arteries of sixteen dogs, was $4.75 \mathrm{ft}$. of blood; while the pulse of the dog beats ninety-seven times in the minute, on an average. Hence we can obtain the capillary coefficient of the dog,

$$
\mathrm{A} \times \frac{d^{4}}{l}=\frac{\mathrm{Q}}{h}=\frac{0^{\circ} 954 \times 97}{4^{\circ} 75}=19^{\circ} 6 \text {. }
$$

The sheep and dog differ from each other, as much as man and the horse do, in size of heart and rate of pulse ; they also differ in hamastatical pressure; yet, notwithstanding these differences, the capillary coefficient depending on them all, comes out to be nearly the same in both animals.

The capillary coefficient of the horse is double that of the sheep and dog, showing that the resistance to circulation in the horse is only half that of the smaller animals. The left ventricle of the horse contains Io cubic inches, the rate of pulse is 36 beats in a minute, and the average hæmastatical pressure is $9^{\circ} \mathrm{I} 4 \mathrm{ft}$. of blood. Hence we find for the capillary coefficient in the horse

$$
\mathrm{A} \times \frac{d^{4}}{l}=\frac{\mathrm{Q}}{h}=\frac{10 \times 36}{9^{\circ} 14}=39^{\circ} 3
$$

I now assume that the capillary coefficient in man is the same as in the horse; or, in other words, that man bears to the horse, in regard to blood circulation, the same relation as the dog bears to the sheep.

On this assumption, the hæmastatical pressure in the human arteries may be thus found. The human heart has a capacity, in its left ventricle, when in action, of 3 ounces, or $5^{\circ} 2$ cubic inches, and beats 75 times in a minute. Solving equation ( 1 ) for $h$, we find

$$
h=\frac{\mathrm{Q}}{\mathrm{A} \times \frac{a^{4}}{l}}
$$

Substituting for $Q$, the product of the capacity of the ventricle and rate of pulse; and for the capillary coefficient, its value in the horse, we obtain

$$
h=\frac{5^{\circ} \times 75}{39^{\circ} 3}=9^{\circ} 923 \mathrm{ft} \text {. of blood. }
$$

This is the hamastatical pressure used in the preceding paper on the force of the heart.

Samuel HaUghton 